\section{Human Papillomavirus (HPV) Vaccination: Just the Facts}

Key words: human papillomavirus vaccine, drug adverse reaction, a complex regional pain syndrome, postural orthostatic tachycardia syndrome, neurological symptoms

\section{(Intern Med 54: 1831, 2015)}

(DOI: 10.2169/internalmedicine.54.4805)

The Authors Reply We appreciate your concerns regarding our paper which indicates a possible relationship between human papillomavirus (HPV) vaccination and various neurological manifestations (1). We acknowledge that HPV vaccination may reduce the number of patients with uterine cervix cancer, leading to the preservation of many women's lives (2). However, there are a significant number of postvaccinated Japanese girls suffering from chronic headache, fatigue, limb pain, and/or tremor with disability. Moreover, some of them have not been about to attend classes due to the severity of these symptoms and a small number of these affected girls appear to have cognitive decline. Although the temporal relationship between the vaccination and the onset of the various neurological symptoms suggests that these neurological manifestations are secondarily induced by HPV vaccination, there is no direct evidence showing a causative relationship.

Even if the World Health Organization (WHO) recommends vaccination and appeals for the usefulness of the HPV vaccine, HPV vaccination will not be widely accepted in Japanese women without the recognition of the causes of these curious neurological manifestations after vaccination. Additionally, we do not have any curative treatments for chronic regional pain syndrome (CRPS)-like limb pain with motor disorders or orthostatic dysregulations observed in these post-vaccinated girls. Thus, many of them and their parents have had to seek more effective therapies. Recently, another Japanese group has proposed a new disease entity: HPV vaccination associated with neuroimmunopathic syndrome (HANS) (3). There are some previous reports from foreign countries; a case report from Mexico described three girls with fibromyalgia-like chronic limb pain after HPV vaccination (4), and reports from the Danish Health and Medicines Authority described serious adverse drug reactions after HPV vaccination, postural orthostatic tachycardia syndrome (POTS) being one such important event (5).

The aim of our study was to describe the variety of possible neurological symptoms seen in Japanese girls immunized with the HPV vaccine, which will be helpful for understanding previously undetected complaints in the postvaccinated girls. In order to determine the safety on this vaccine, further extensive investigation, including a large cohort study, is required.

The authors state that they have no Conflict of Interest (COI).

Tomomi Kinoshita and Shu-ichi Ikeda

\section{References}

1. Kinoshita T, Abe R, Hineno A, Tsunekawa K, Nakane S, Ikeda S. Peripheral sympathetic nerve dysfunction in adolescent Japanese girls following immunization with the human papillomavirus vaccine. Intern Med 53: 2185-2200, 2014.

2. Castle P, Konno R, Bosch X. Human papillomavirus (HPV) vaccination: just the facts. Intern Med 54: 1829, 2015.

3. Nishioka K, Yokota S, Matsumoto Y. Clinical features and preliminary diagnostic criteria of human papilloma vaccination associated with neuroimmunopathic syndrome (HANS). Int J Rheum Dis 17 (Suppl 2): 6, 2014.

4. Martinez-Lavin M. Fibromyalgia-like illness in 2 girls after human papillomavirus vaccination. J Clin Rheumatol 20: 392-393, 2014.

5. Danish Health and Medicines Authority. Danish Pharmacovigilance Update, 29th January, 2014 [Internet] [cited 2014 Nov 15]. Available from: http://sundhedsstyrelsen.dk/en/news/2014/ /media/ 0540230CC7344D6589018F88BB171F51.ashx

Department of Medicine (Neurology and Rheumatology), Shinshu University School of Medicine, Japan

Received for publication December 24, 2014; Accepted for publication December 24, 2014

Correspondence to Dr. Shu-ichi Ikeda, ikedasi@shinshu-u.ac.jp

(C) 2015 The Japanese Society of Internal Medicine Journal Website: http://www.naika.or.jp/imonline/index.html 